\title{
ESTUDO DA VARIABILIDADE GENÉTICA DE UMA POPULAÇÃO DE GABIROBA (CAMPOMANESIA ADAMANTIUM), UTILIZANDO MARCADORES RAPD
}

\author{
Luciana Machado Guaberto; Andressa Bianca Silva Veronezi; \\ Universidade do Oeste Paulista - UNOESTE, Faculdade de Farmácia e Bioquímica de Presidente Prudente, Presidente \\ Prudente, SP. E-mail: andressaveronezi19@hotmail.com.
}

\section{RESUMO}

Em estudos de conservação e seleção genética de espécies nativas da região do cerrado é comum a ocorrência natural da gabiroba (Campomanesia adamantium), pertencente à família Myrtaceae. As informações sobre a variabilidade genética dessas espécies são escassas. O objetivo foi estudar a variabilidade genética de duas populações de gabiroba provenientes das cidades de Martinópolis e Taciba no estado de São Paulo usando técnicas de RAPD. Os RAPDs apresentaram poder de discriminação eficiente entre os 20 genótipos analisados, com uma divergência genética variando de 38 a 78\%. Significando que entre os indivíduos existe uma ampla base genética, possibilitando a manipulação desse material em programas de conservação. Dos 3 grupos formados, o Grupo I foi o que mais diferiu dos outros, apresentando maior variabilidade genética. $O$ uso de marcadores RAPD apresentou ser eficaz no estudo de polimorfismo genético entre os indivíduos em questão.

Palavras-chave: Myrtaceae, Fluxo Gênico, Marcadores Moleculares, Polimorfismo.

\section{STUDY OF THE GENETIC VARIABILITY OF TWO POPULATIONS OF GABIROBA (CAMPOMANESIA ADAMANTIUM), USING MOLECULAR MARKERS.}

\begin{abstract}
In genetic conservation and selection of studies of native species of the Cerrado region it is common to naturally occurring gabiroba (Campomanesia adamantium ), belonging to the Myrtaceae family. Information on the genetic variability of the species are scarce. The objective was to study the genetic variability of two populations of gabiroba from the cities of Martinópolis and Taciba in São Paulo using RAPD techniques. The RAPDs presented efficient discriminating power among the 20 genotypes studied, with a genetic divergence ranging from 38 to $78 \%$. Meaning that among individuals there is a broad base, allowing the handling of this material in conservation programs. Of the three formed groups, Group I was the one that differed from the others, with higher genetic variability. The use of molecular markers showed to be effective in the genetic polymorphism study of the individuals concerned

Keywords: Myrtaceae. Gene Flow. Molecular Markers. Polymorphism.
\end{abstract}




\section{INTRODUÇÃO}

A espécie Campomanesia adamantium (Camb.) é frutífera nativa e não cultivada, porém abundante na região do Cerrado. A planta se desenvolve de forma arbustiva, atingindo até $2 \mathrm{~m}$ de altura, muito ramificada e com ramos delgados. Suas folhas são simples, opostas, ovais ou elípticas, membranáceas ou cartáceas, com base aguda à obtusa, apresentando ápice agudo com cerca de $4 \mathrm{~cm}$ de comprimento e $2 \mathrm{~cm}$ de largura (DURIGAN et al., 2004). Os frutos apresentam grande potencial para serem utilizados "in natura" em qualquer período de maturação pela indústria de alimentos e como flavorizantes na indústria de bebidas, devido à elevada acidez, ácido ascórbico (vitamina C), minerais, fibras alimentares e hidrocarbonetos monoterpênicos, presentes em maior quantidade no óleo volátil dos frutos, e que lhes conferem o aroma cítrico (VALLILO et al., 2006).

Popularmente conhecida como gabiroba ou guabiroba, pertence a família das Myrtaceae, composta por aproximadamente 130 gêneros que se distribuem nas regiões tropicais e pantropicais. A família é dividida em duas subfamílias: Leptospermoideae e Myrtoideae, que representam os dois centros de dispersão geográfico do grupo (SOUZA; LORENZI, 2005) sendo Leptospermoideae, representada por plantas de frutos secos e capsulares e Myrtoideae por plantas de frutos carnosos e baciformes (BARROSO, 1991). As espécies do gênero Campomanesia se destacam pelo potencial recurso alimentar da avifauna e do homem. Além disso, o óleo essencial extraído das folhas de Campomanesia xanthocarpa revelou atividade antimicrobiana em relação ao Staphylococus aureus, Pseudomonas aeruginosa e Candida albicans (MARKMAN, 2002) e de acordo com Vallilo (2004) o óleo dos frutos de Campomanesia adamantium mostrou-se rico nos compostos terpenóides: Ocimeno, 3-Careno e D-Limoeno.

A partir do desenvolvimento da PCR, vários marcadores moleculares baseados nesta técnica foram descritos para estudos de estrutura de populações, sistemática, variabilidade genética, melhoramento genético; entre eles encontra-se o RAPD (ALVES, 2006).

O marcador RAPD consiste simplesmente em uma variação do protocolo de PCR, com duas características distintas: o uso de um só primer ao invés de um par de primers; e o primer único tem sequência arbitrária, tornando sua seqüência alvo desconhecida (WILLIAMs et al., 1990).

As principais vantagens da técnica são a facilidade e a rapidez para obtenção dos marcadores, a necessidade de quantidades mínimas de DNA e a universalização das análises. Pode-se trabalhar com qualquer espécie, uma vez que não há necessidade de conhecimento prévio de dados de sequência de DNA para a construção dos primers. As principais desvantagens referem-se a dominância dos marcadores, não diferenciando os locos em heterozigose dos locos em homozigose e à baixa reprodutibilidade das marcas por causa da sensibilidade da técnica às condições experimentais, principalmente, quando elas não estão bem padronizadas (FERREIRA; GRATTAPAGLIA, 1998; FALEIRO et al., 2004).

O presente trabalho teve por objetivo estudar a variabilidade genética de duas populações de gabiroba provenientes das cidades de Martinópolis e Taciba do estado de São Paulo, por marcadores moleculares RAPD.

\section{METODOLOGIA}

Esta pesquisa foi desenvolvida no laboratório de Genética Molecular e Citogenética da Universidade do Oeste Paulista, Presidente Prudente - SP. Foram analisados 20 genótipos de Campomanesia adamantium, provenientes das cidades de Martinópolis e Taciba no estado de São Paulo. Para análise do DNA, utilizaram-se folhas coletadas das plantas no campo. As folhas recémcolhidas foram identificadas e mantidas no gelo para o transporte até o laboratório e, em seguida, procedeu-se às extrações do DNA. 
As extrações de DNA foram feitas de acordo com o procedimento descrito por Nienhuis et al., (1995), a quantificação da concentração de DNA das amostras foi determinada por um fluorímetro (DYNAQuant 200). Para cada amostra foram utilizados $2 \mu \mathrm{l}$ de DNA e $2 \mathrm{ml}$ de tampão TNE 10x (Tris base $100 \mathrm{mM}$; $\mathrm{Na}_{2}$ EDTA, $\mathrm{Na}_{2} \mathrm{H}_{2} \mathrm{O} 10 \mathrm{mM}$ e NaCl $2 \mathrm{M}$, sendo o $\mathrm{pH}=7,4$ ).

Foram inicialmente testados 82 pares de oligonucleotídeos consultados na sequencia Operon, para geração de polimorfismo, baseadas no método descrito por Williams et al. (1990), usando oligonucleotídeos de dez bases de sequência arbitrária com algumas modificações, sendo as reações otimizadas para obtenção de produtos de amplificação de melhor qualidade.

As reações de PCR-RAPD foram realizadas em termociclador MJ-PTC 100, onde cada solução continha 20 ng de DNA, 10\% de tampão para PCR (20 mM Tris- $\mathrm{HCl}$, ph 8.4, $50 \mathrm{mM}$ de $\mathrm{KCl}$ ) mais 1,5 mM MgCl2, 0,2 $\mu \mathrm{M}$ de cada dNTP, 0,4 $\mu \mathrm{M}$ do oligonucleotídios decâmeros arbitrários (OPERON Tecnologies Inc) a ser testado e $1 \mathrm{U}$ de Taq DNA polimerase em um volume final de 25 $\mu \mathrm{l}$. As reações ocorreram em 43 ciclos, após a desnaturação inicial de $94^{\circ} \mathrm{C}$ por 5 minutos, cada ciclo se constituía de: desnaturação $92^{\circ} \mathrm{C}$ por 30 segundos; anelamento $37^{\circ} \mathrm{C}$ por 1 minuto e 30 segundos, e extensão $72^{\circ} \mathrm{C}$ por 30 segundos. Após os 43 ciclos realizou-se uma extensão final de 5 minutos a $72^{\circ} \mathrm{C}$. Após a reação o material foi aplicado em gel de agarose a $1,5 \%$ com brometo de etídeo, embebido em tampão TBE 0,5X e submetido à corrida de eletroforese. Os resultados foram visualizados com iluminação ultravioleta em câmara escura e as imagens capturadas em uma câmera CCD Alpha-Inmotech, analisadas por software Chemilmager.

A análise dos dados moleculares foram feitas através do método hierárquico, no qual os dados são agrupados produzindo uma representação hierárquica.

Através da análise multivariada aplicada com a utilização do software $R$, foi calculada a matriz de dissimilaridade Bray-Curtis sobre dados não transformados, não padronizados: >x.dist<-vegdist( $x$, "bray")

Foi criado o agrupamento hierárquico com2 ligação média sobre a matriz de dissimilaridade Bray-Curtis: $\quad$ x.clust<-hclust(x.dist, "average")

E por fim, plotado um dendrograma $\quad$ : plot(x.clust, hang=-0.5)

\section{RESULTADO}

De 82 oligonucleotídeos decâmeros arbitrários (OPERON Tecnologies Inc) inicialmente testados para a amplificação do DNA genômico da Campomanesia adamantium, foram selecionados 7 (Tabela 1).no qual pelo menos uma banda polimórfica foi gerada. Estes oligonucleotídeos de síntese de cadeia curta podem parear-se aleatoriamente em regiões de homologia no DNA do genótipo analisado, fornecendo, assim, um ponto de início de síntese para a DNA polimerase (FERREIRA; GRATTAPAGLIA, 1998). Foram gerados 100 produtos de amplificação, com uma média de 28 bandas. Deste total, 56 bandas foram polimórficas, igual a $56 \%$ e $20 \%$. Monomórficas. O número de bandas variou de acordo com o oligonucleotídeo.

Observa-se, na Tabela 1, que os resultados indicam um alto grau de polimorfismo entre os genótipos de Campomanesia adamantium, fato que pode ser observado pelo padrão de fragmentos amplificados com a utilização do primer A13, conforme a demonstração apresentada na Figura 1.

O cálculo da distância genética foi feito com base nos produtos amplificados. Foi construída uma matriz de distâncias genéticas, utilizando o software R.

Conforme pode ser observado na Figura 2, os resultados demonstraram uma grande variabilidade genética entre as amostras. Por exemplo, os genótipos 18 e 19; 13 e 15; e 17 e 13 apresentaram distâncias entre si iguais ou superiores a 75\%. Os genótipos 7 e 9; 4 e 14; 1 e 6; 3 e 5; e 2 e 8 apresentaram dissimilaridade de, respectivamente $55,53,50$, 66 e 55\%.

Os genótipos que apresentaram as menores divergências foram 10 e 12; e 16 e 20 com distâncias genéticas de, respectivamente, 38 e $41 \%$. 
Tabela 01. Oligonucleotídeos utilizados e respectiva sequência de bases, número de bandas polimórficas e monomórficas para os 20 genótipos estudados.

\begin{tabular}{cccccc}
\hline Oligonucleotídeo & $\begin{array}{c}\text { Sequência } \\
\left(\mathbf{5}^{\prime}-\mathbf{3}^{\prime}\right)\end{array}$ & $\begin{array}{c}\text { Total de } \\
\text { Bandas }\end{array}$ & $\begin{array}{c}\text { No de } \\
\text { Bandas } \\
\text { Polimórficas }\end{array}$ & $\begin{array}{c}\text { No de Bandas } \\
\text { Monomórficas }\end{array}$ & $\begin{array}{c}\text { Porcentagem de } \\
\text { Bandas } \\
\text { Polimórficas }\end{array}$ \\
\hline A1 & CAGGCCCCTC & 15 & 12 & 0 & 80 \\
A3 & AGTCACGCAC & 14 & 10 & 1 & 71 \\
A7 & GAAACGGGTG & 10 & 6 & 0 & 60 \\
A8 & GTGACGTAGG & 13 & 5 & 1 & 38 \\
A13 & CAGCACCACCCAC & 15 & 11 & 1 & 73 \\
A18 & AGGTGACCGT & 17 & 8 & 9 & 47 \\
A19 & CAAACGTCGG & 16 & 4 & 9 & 25 \\
& & & & & \\
\hline Total & & $\mathbf{1 0 0}$ & $\mathbf{5 6}$ & $\mathbf{2 0}$ & - \\
\hline
\end{tabular}

M

$\begin{array}{llllllllllllllllllll}1 & 2 & 3 & 4 & 5 & 6 & 7 & 8 & 9 & 10 & 11 & 12 & 13 & 14 & 15 & 16 & 17 & 18 & 19 & 20\end{array}$

Figura 01. Eletroforese em gel de agarose a 1,5\% mostrando padrões de bandeamento de fragmentos de DNA amplificados por PCR com uso do oligonucleotídeo A13. As canaletas apresentam marcador molecular de 100 pb e amostras de 1 a 20 representando os genótipos avaliados. 


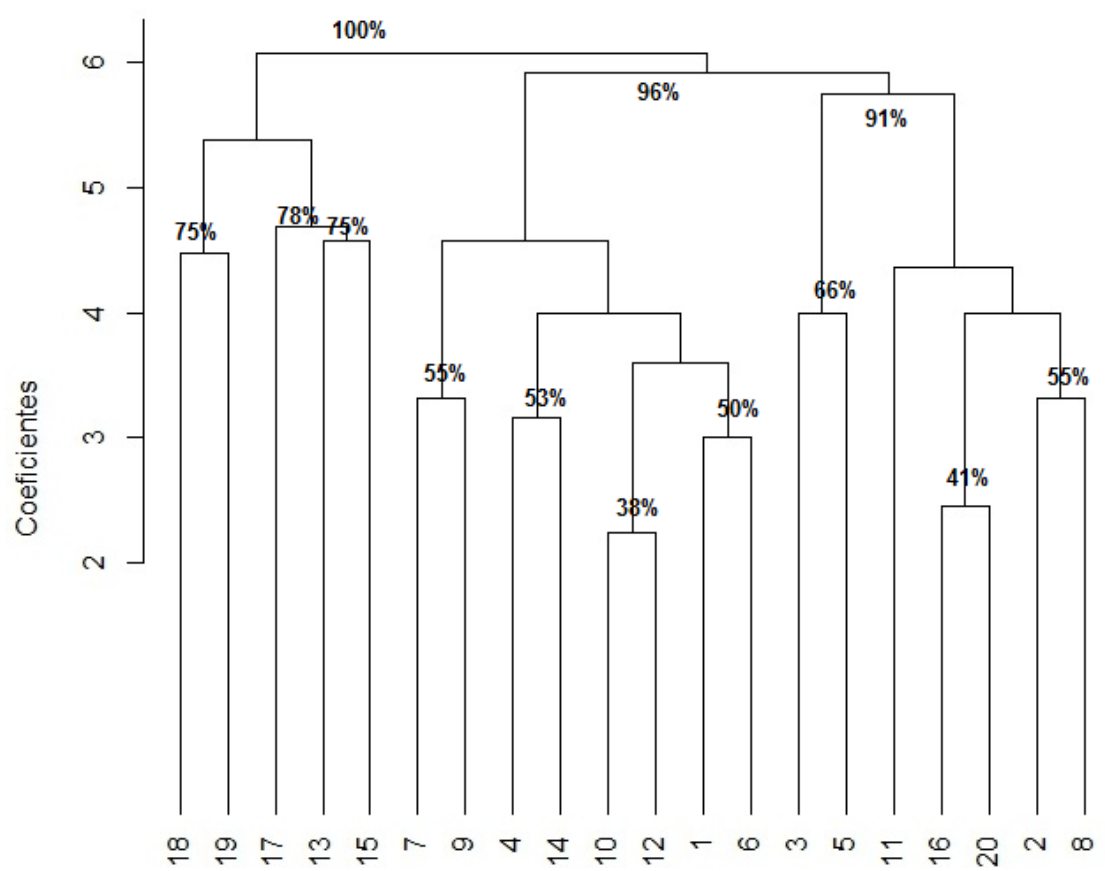

Figura 02. Dendrograma obtido pela análise multivariada aplicado com $R$, com base na dissimilaridade genética entre os 20 genótipos de Campomanesia adamantium.

Tabela 02. Agrupamento de genótipos de Campomanesia adamantium observados a partir do dendrograma de dissimilaridade.

\begin{tabular}{l|l}
\hline Grupo & Genótipos \\
\hline I & $13,15,17,18,19$ \\
II & $1,4,6,7,9,10,12,14$ \\
III & $2,3,5,8,11,16,20$ \\
\hline
\end{tabular}

Foi observado a formação de 3 grupos conforme a Tabela 2. O grupo I se sobressaiu em relação aos outros grupos, apresentando maior variabilidade genética

\section{DISCUSSÃO}

Em um estudo feito com a $C$. adamantium provenientes de 17 regiões em Goiás, utilizando a técnica de RAPD, pôde-se observar um alto nível de polimorfismo, 90,44\% (ASSIS et al., 2013). Gonçalves et al. (2008), em seus estudos de polimorfismo em germoplasma de tomateiro utilizando marcadores RAPD, também identificou diversidade genética, conforme a descrição de outros trabalhos a respeito (WILLIAMS et al., 1990).

Estes resultados complementam um estudo já feito a partir das comparações de características dos frutos da gabiroba na cidade de Dourados, Mato Grosso do Sul, em que indicaram a existência de variabilidade genética e possibilidade de seleção de materiais promissores para o melhoramento vegetal. (PELLOSO et al., 2008).

Assis et al., (2011), selecionou 12 oligonucleotídeos que produziram um total de 178 amplificações entre 140 genótipos de gabirobas nativas. O nível de polimorfismo correspondeu a 90,44\%. Junqueira et al., (2010) obteve resultados parecidos com a pitaya nativa do cerrado cujo polimorfismo foi de 95,06\%. Em estudos com goiabeiras, Gomes Filho et al.,(2010) obteve $87,97 \%$ e Pessanha et al., (2011) ao avaliar 3 regioes do Rio de Janeiro observou 97,5\% de polimorfismo. 


\section{CONCLUSÃO}

Os oligonucleotídeos A1, A3, A7, A8 e A13 mostraram eficiência na aquisição de bandas polimórficas. A18 e A19 apresentaram maior número de indivíduos monomórficos.

Há grande variabilidade genética entre os indivíduos analisados possibilitou a formação de 3 grupos distintos e com alta divergência entre si.

O uso de marcadores RAPD apresentou ser eficaz no estudo de polimorfismo genético entre os indivíduos em questão. Assim, para esta analise, o resultado obtido pode ser considerado uma representação consistente da diversidade genética ao nível molecular de gabirobeiras nativas do interior de São Paulo onde foram coletadas.

\section{REFERÊNCIAS}

ALVES, D.J. Polimorfismo de RAPD em Populações de Tetragonisca angustula L.(APIDAE: MELIPONINAE). Tese (Mestrado). Universidade Estadual de Maringá - Programa de Pós Graduação em Genética e Melhoramento. Paraná, 2006.

BARROSO, G.M. Sistemática de Angiosperma do Brasil. Viçosa: UFV, Imprensa Universitária, 1991. (Volme 2) 377p.

DURIGAN, G.; FRANCO, A.D.C.; SIQUEIRA, M.F. A vegetação dos remanescentes de cerrado no estado de São Paulo. In: BITENCOURT, M.D.; MENDONÇA, R.R. Viabilidade de Conservação dos Remanescentes de Cerrado no estado de São Paulo, São Paulo: Annablume; Fapesp, 2004. p. 2956.

FALEIRO, F.G. Marcadores Genético-Moleculares Aplicados a Programas de Conservação e Uso de Recursos Genéticos. Planaltina - DF: EMBRAPA CERRADOS, 2007.

FERREIRA, M.E.; GRATTAPAGLIA, D.. Introdução ao Uso de Marcadores Moleculares em Análise Genética. 3 ed. Brasília: EMBRAPA - CENARGEN, 1998.

MARKMAN, B.H.O. Caracterização farmacognostica de Campomanesia xanthocarpa, Myrtaceae. 2002. 162 p. Tese (Mestrado) - Faculdade de Ciências Farmacêuticas da Universidade de São Paulo. São Paulo.

NIENHUIS, J., et al. Genetic relationships among cultivars and lines of lima bean (Phaseolus lunatus L.) as measured by RAPD markers. Journal of the American Society for Horticultural Science, v. 120, n.2, p.300-306, 1995.

SOUZA, V.C.; LORENZI, H. Botânica sistemática: Guia ilustrado para identificação das famílias de Angiospermas da flora brasileira, baseado em APG II. Nova Odessa, SP: Instituto Plantarum, 640p., 2005.

VALLILO, M. I. et al.. Identificação de terpenos no óleo dos frutos de Campomanesia adamantium (Cambessedes) O.Berg. Landrum - Myrtaceae. Arq. Inti. Biol., v.71, (supl.), p. 1-749, 2004.

WILLIAM, J.G.K. et al. DNA polimorphisms amplified by arbitrary primers are useful as genetic markers. Nucleic Acids Research, v.18, n.22, p.6531-6535, 1990. https://doi.org/10.1093/nar/18.22.6531 
ASSIS, ELISVANE SILVA DE; REIS, EDÉSIO FIALHO DOS; DIAS, LUIZ ANTÔNIO DOS; CONTIM, LUIS ANTÔNIO Serrão; Diversidade genética de gabirobeiras (Campomanesia spp) por meio de caracteres morfológicos em marcadores moleculares RAPD. Universidade Federal de Goiás, CAMPUS JATAÍ., 2011.

JUNQUEIRA, K.P.; FALEIRO, F.G.; BELLON, G.; JUNQUEIRA, T.V.; FONSECA, K.G.; LIMA, C.A.; SANTOS, E.C. Variabilidade genetica de acessos de pitaya com diferentes niveis de producao por meio de marcadores RAPD. Revista Brasileira de Fruticultura v. 32 n.3 Jaboticabal Sept. 2010a.

GOMES FILHO, A; OLIVEIRA, J.G; VIANA, A.P; SIQUEIRA, A.P.O; OLIVEIRA, M.G; PEREIRA, M.G. Mrcadores moleculares RAPD e descritores morfologicos na avaliacao da diversidade genetica de goiabeiras (Psidium guajava L.). Acta Scientiarum. Agronomy Maringá, v. 32, n. 4, p. 627-633, 2010.

PESSANHA, P.G.O; VIANA, A.P; AMARAL JUNIOR, A.T; SOUZA, R.M; TEIXEIRA,M.C; PEREIRA, M.G. Avaliacao da diversidade genetica em acessos de Psidium spp. Via marcadores RAPD. Revista Brasileira de Fruticultura, Jaboticabal - SP, v. 33, n. 1, p. 129-136, Marco 2011.

PELLOSO, I. A. O. et al.. Avaliação da diversidade genética de uma população de guavira (Campomanesia adamantium Cambess, O. Berg, Myrtaceae). Revista Brasileira de Agroecologia, v. 3, n. 2, 2008. 